\title{
Usability Evaluation using Eye-Tracking on E-Commerce and Education Domains
}

\author{
Rafiat Oyekunle1, ${ }^{*}$, Olaiyiwola Bello1, Quincy Jubril1, Ismaheel Sikiru1, \\ Abdullateef Balogun 1
}

${ }^{1}$ Department of Computer Science, University of Ilorin, Ilorin, PMB1515, Nigeria

\begin{tabular}{llllll}
\hline Received: 01.12 .2020 & $\bullet$ & Accepted: 20.12.2020 & $\bullet$ & Published: 31.12 .2020 & $\bullet$
\end{tabular}

\begin{abstract}
The rapid consumption of content on the web and the creation of online businesses and educational platforms require improved usability for the user. It also calls for concerted effort to understand users' interactions with these digital products and services. This study was carried out to investigate the search and scan patterns employed by users interacting with the selected web interface from the e-commerce and education domains and also to establish the possibility of a localized interface design patterns in Nigeria. Usability evaluation was conducted using OGAMA software as an eye-tracking tool, to record as well as to analyze eye and mouse tracking data from slideshow eye-tracking experiments concurrently. During the evaluation period, fixation count, fixation length and saccade length of each website were taken into the consideration. Findings revealed that educational based site delivers users' need than that of e-commerce due to less level of distraction as a result of fewer images and pictures. The study recommends that interface designs should be void of the display of excessive ad contents and include proper formatting of navigation items to contribute towards an enhanced user experience.
\end{abstract}

Keywords: Search pattern, Scan patterns, Eye-tracking, Interface design, Eye movement

\section{Introduction}

The geometric growth of internet access has given citizens the ability and power to interact with individuals across the world, enabling information sharing beyond borders at a level that has not been realized previously in the history of human experience (Amen, Agot Jr, Rosauro, \& Gamas, 2017). This borderless interaction and information sharing encapsulate all human endeavours - be it commerce, education, governance, among others. This growth has given rise to the need to understand usability on those interfaces that enable communication and sharing of information by individuals or a group (Sikiru, Bello, \& Oyekunle, 2019).

However, in the psyche of commerce and education, end users have the highest authority to select the niche. The niche selection is only by the effective use of the eye, and studies have shown that eye movements reflect knowledge acquisition (Mason, Pluchino, \& Tornatora, 2016). With the advancement in science and technology, eye-tracking technology has recently become more advanced and diversified. Eye-tracking technology is a technique that uses the image processing technology and collocate mini-camera to enable focusing of the eyes and capturing the infrared which reflects from the cornea and pupil, after which the changes of eye movements continuously are recorded and then the result of the eye-tracking process is analyzed.

\footnotetext{
* Corresponding Author: ummusumayya1@yahoo.com
} 
An eye-tracking method is widely used to evaluate the usability of software systems as it provides data for understanding users' focus points in the software systems. It collects eye movements data with an eye-tracking device while users are using a system and collected eye movements are analyzed based on fixation and saccade-based measures (Bhoir, Hasanzadeh, Esmaeili, Dodd \& Fardhosseini, 2015). This produces a significant amount of data about the point being considered or processed information (Pauly \& Sankar, 2015). Hence, information can be gathered about how users have learnt how to use a designed website using eye movement data obtained through eye-tracking. Patterns also can be suggested on how to create more user-friendly interfaces because of the insight gained from the use of eye-tracking technology. Since many websites and applications are catering for a wide range of human needs - Education, E-commerce, Government, etc. - it is usability testing that provides a way for understanding the actual condition of the product in question and just how efficient it is in helping users solve or reach their goals on the software or web interface. This ultimately contributes to the enhanced effectiveness, efficiency, and satisfaction of a user on such an interface. "In this respect, numerous variables such as the characteristics, interests, and purposes of use of people are regarded as important variables that need to be given priority while defining the properties that websites should have" (Aranyi \& Van Schaik, 2016; Sikiru, Bello, \& Oyekunle, 2019). This is particularly done to cater for usability on such a system; absence of this may result in a negative experience for a user without much expert knowledge of the system.

In this study, it is aimed to reveal which usability features should be provided in e-commerce and educational websites for experienced users and from the perspective of website design, eyetracking technology is said to have quite many advantages as it may provide information about the user's mental state in real-time and as an objective method which can reflect cognitive processing through eye movement metrics (Wang, Yang, Liu, Cao \& Ma, 2014; Martin, Cegarra \& Averty, 2011). This study, therefore, was carried out to answer the following research questions: what are the search and scan patterns used in interacting with the selected interfaces? What causes fixation on the interfaces by the users that creates an area of interest heat maps? Are there any similarities in the design approach used by the selected domains? What are the common usability problems faced by users? The research paper is structured into five sections. Section 2 of this study presents the literature review of the study. The research methodology adopted to conduct the pilot test is elaborated in the third section, while section 4 presents the results and discussion of findings. Finally, the fifth section concludes the study.

\section{Literature Review}

\subsection{Usability Evaluation Methods}

There are several usability evaluation methods in the literature. Matera, Rizzo \& Carughi, (2006) distinguished two main broad categories of the evaluation method which refers to the stage of the design process: formative evaluation, which takes place during design, and summative evaluation, which occurs after the product is developed. Evaluation methods may also be classified according to the way of data collection. User testing methods are intended to conduct the studies with real users; usability inspection involves the specialists who assess the product in the process and Web usage analysis is also to obtain the data about user behaviour but based on the analysis of Web access logs. Among those three classes, there are different techniques which allow picturing different characteristics of websites. User testing may be performed by using, i.e. think-aloud protocol, remote usability testing or eye-tracking. Among usability inspection methods the most commonly used are 
heuristic evaluation (Nielsen, 1993; Nielsen \& Mack, 1994) in which usability specialists judge whether application properties conform to the established usability principles and cognitive. The choice of particular methods depends on the purpose of the evaluation as they have their advantages and disadvantages. Being an objective research method with the possibility of reflecting cognitive processing through eye movement metrics, eye tracking was utilized in this study. It also has the benefits of tracking how the users interact with a given interface or environment and measuring the effectiveness of a visual element on the interface. The measurements recorded can lend an understanding of the user's mind while deciding on searching or navigating an interface.

\subsection{Eye movement and Attention}

Eye-tracking originated from various studies of how the eyes move from one position to the other as well as how they are positioned immediately after a movement. In the 1800 s, scientists were concerned with the nature of the human eye and eye movements generally. Investigations of scientists like J. E. Purkinje about reflections on the eyeball and findings of Louis Emile Javal play a major role in eye-tracking studies. Javal observed in 1879 that the human eyes do not read smoothly while reading, but they pause on some words. A series of stops referred to as fixations; and short rapid movements called saccades were recorded in between actions performed by the eye while reading takes place (Mason et al., 2016).

Information of the time, as well as space from eye movement and external messages, must be taken into account to understand the relationship between the fixations and saccades. Majority of the eye movement studies concentrate on collecting quantitative information about the gaze spot and the stay time of the eyes when gazing at a diagram or a paragraph of text (Deotale, 2011; Iqbal, 2015; Kiefer, 2017). Moreover, the study of Kiefer (2017) has led researchers to seek an understanding of the depth of the visual perception system in processing the messages through an analysis of the gaze times and fixation duration for the time dimension; while the spatial dimension emphasized the fixation point as well as the saccade length. Nevertheless, the three main methods that have been popularly used to measure eye movements in the literature are the "special lens equipped with a built-in induction coil that can be worn on the eyes to record its rotation, such as scleral search coil; the use of optical non-contact way to measure eye movements, such as video-based eye tracker and lastly is the employment of an equipment called electrooculogram (EOG) which uses the change of electromyography to obtain the eye movement data".

\subsection{A brief history of Eye-tracking research}

Eye-tracking has been noted as a concept of expressing the actuality of what an individual sees while spotting at a certain context. Due to its wide deployment in a range of disciplines, it's quite important to give a brief history of eye-tracking research. In 1879, French ophthalmologist Louis Emile Javal observed that readers' eyes always make swift movements referred to as saccades together with short pauses called fixations while reading the text. While in (Almeida, Mealha, \& Veloso, 2016) the movement of fixation is characterized to be as not dynamic as other forms of movement - optokinetic nystagmus (OKN), pursuit, saccade, vengeance movements, and vestibule-ocular reflex (VOR) (Rothkegel, Schütt, Trukenbrod, Wichmann, \& Engbert, 2019). He successfully achieved this without any advanced technology, but rather with naked-eye observations.

Also, Dodge and Cline (1901) developed a photographic plate to record light reflected from the cornea. This Photochronograph is termed as the fundamental building block of the present time video-based corneal reflection eye trackers (Majaranta, 2011; Shanmuga, Ngo, Eckstein, \& 
Manjunath, 2015). It was the first non-invasive eye-tracking system developed. This system only recorded horizontal eye position directly falling onto a photographic plate; however, such an individual would remain motionless. Another research was observed by Judd, McAllister, and Steele (1905) who made use of motion image photography instead, to record the temporal aspects of eye movements. This technique took the records of a white speck of material inserted into participants' eyes contrary to light reflection from the cornea.

In 2013, Yarbus, a psychologist from Russia, made substantial contributions to eye-tracking studies through his extensive studies between the 1950s and 1960s. His findings revealed that the reader's interest and the given task were the determinants of his/her eye movement and fixation. The contributions of Yarbus (2013) have laid speedy progress in the research field of eye movement as well as the eye-tracking process. For this merit, robust relevant works were discovered in the 1970s as there was a notable focus on the technical improvements to improve accuracy, effectiveness, and precision of eye trackers. Due to this improvement, eye-trackers were able to distinguish between the eye and head movements; thus making the recordings more accurate and less intrusive. This discovery enhanced two joint military/industry teams to develop a remote eye-tracker which reduced the tracker intrusion and its effects on the users (Monty, 1975). In the 1970s, a record also showed how inclusive the psychological theories are in the analysis of the correlation between data obtained from eye-tracking and cognitive processes. Progressively, in the 1980s, real-time eye tracking process was realized due to the presence of powerful computers (Card, 2018). This eventually enabled the application of video-based eye-trackers, Video-OcculoGraphy, to the concept of humancomputer interaction.

Before the 1970s, psychologists are known to have studied eye-movements and fixations did avoid cognitive factors - attention deployment, earning, memory, and workload - they were rather concerned about the relationship between eye-movements and visual stimulus (Zhai \& Enderle, 2016). Alternatively, in the 1970s, the psychologists included the relationship study between fixations and cognitive activities as the engineer's improved eye-tracking technologies (Just \& Carpenter, 1976; Tonbuloğlu, 2013)

In recent times, eye tracking has been widely embraced in human-computer interaction to study the usability of computer interfaces and/or interact with the computer as an input device (Boccignone, Ferraro, Crespi, Robino, \& de'Sperati, 2014). Likewise, other fields have also adopted the application of usability studies with the use of the eye-tracking method. For example, in the area of webpage usage (Hsu, Chang, \& Liu, 2018), university websites evaluation (Menzi-Cetin, Alemdağ, Tüzün, \& Yıldız, 2017), computer games (Almeida et al., 2016), e-commerce websites (Wątróbski, Jankowski, Karczmarczyk, \& Ziemba, 2017), and television programs.

\subsection{Eye-tracking Application areas}

A study conducted by Tonbuloğlu, (2013) on "Using Eye Tracking Method and Video Record in Usability Test of Educational Software and Gender Effects" employed a case study method in addition to eye tracking and video record. Using heat map, scan path, and fixation count as performance metrics, results showed that females recorded higher scan path performance, and their fixation counts covered a larger area on the page. Furthermore, similar symbols used for similar tasks caused confusion, while, earlier experiences as well as habits - based on the design of the educational software - influenced behaviours of the subjects. This supports the findings of (Ineson, Jung, Hains, \& Kim, 2013) who concluded that pre-knowledge plus experiences influenced the behaviours of the subjects. 
Also, the study carried out by (Iqbal, 2015) to "understand user interaction in a video game by using the two data collection methods: eye-tracking and facial expressions analysis", recruited a total of eight participants which included one pilot participant to perform the usability testing. Findings revealed that on the whole, the usability testing efforts contributed to the enhanced efficiency, effectiveness, as well as satisfaction in the gaming experience. The facial expressions and eye movements provided data that can be useful for various researchers to comprehend the user interaction of players in the course of playing a video game. These include data on objects that capture the attention of the user, objects that were ignored or did not get attention, aspects that amount to difficulties in progressing during the game and also the player's emotional state at the time of interacting with video game elements.

Wątróbski et al. (2017) in their study used a multi-criteria decision analysis (MCDA) method on data from eye-tracking devices and eQual survey to develop a usability evaluation model. Specifically, variants of TOPSIS MCDA were used on aggregated data from survey and gaze measurements. The authors aim to complement survey data evaluation with an empirical method (MCDA). Their results indicated the advantage of the proposed method over other methods. Filiopoulou, Rigou, and Faliagka (2019) investigated the effectiveness of eye-tracking mechanisms on display advertisements visibility and interaction. The study was based on determining the applicability of banner blindness disregarding the displayed ad. This is to determine the efficacy of trick display ads and the response of users towards them.

Lee, Lee, Ju, and Ahn (2019) looked into the behaviour of consumers in the act of purchasing personal computers from search to acquisition using a mobile eye tracker. The main focus of this study is the state of attention decay in a different environment with e-commerce. Findings from their study present details on different mechanisms for e-commerce. Sari, Nugroho, Santosa, and Ferdiana (2018) experimented to ascertain with precision the interest of consumers on three products on an ecommerce website using an eye tracker tool. Consumers' preference and interest in products are gauged via the attraction measurement using the eye tracker. Eye fixation duration was found to be a key factor in recognising consumers' interest in a product.

Cheng, Poon, Lau, and Zhou (2019) applied eye-tracking methods to identify students' challenges in comprehending computer programming codes with learning methods in addressing computer programming problems. Their results showed that students use diverse methods in comprehending different programming tasks and source codes. Findings from there can be used to assist students harness and sharpen their respective computer programming skills. Majooni, Akhavan, and Offenhuber (2018) investigated the usability and efficiency of e-learning platforms via eye-tracking techniques. Their study was aimed at bridging the problems facing students in interaction with e-learning platforms. Insights from their study can be used to design a graphical user interface with better usability for students and teachers.

In summary, different metrics to measure eye movement and their respective descriptions are as shown in figure 1. 


\begin{tabular}{|c|c|c|}
\hline & Metrics & Description \\
\hline \multirow{6}{*}{ 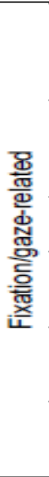 } & $\begin{array}{l}\text { Time to the first } \\
\text { fixation on target }\end{array}$ & $\begin{array}{l}\text { This measure is useful when there are specific targets of interest in a } \\
\text { scene. This metric is measured by calculating the time in milliseconds that it } \\
\text { took for each participant to reach a specific area of interest while viewing a } \\
\text { picture (Thiessen et al. 2014) }\end{array}$ \\
\hline & $\begin{array}{l}\text { Gaze } \% \text { on each } \\
\text { area of interest }\end{array}$ & $\begin{array}{l}\text { Cumulative duration of consecutive fixation and relatively small saccades } \\
\text { time between them describe gaze duration within an area of interest. The } \\
\text { proportion of gaze duration looking at a particular element indicates } \\
\text { possible importance of that element (Jacob and Karn 2003). }\end{array}$ \\
\hline & $\begin{array}{l}\text { Number of fixations } \\
\text { per area of interest }\end{array}$ & $\begin{array}{l}\text { More frequent fixations on the specific area reflect the importance of that } \\
\text { element (Jacob and Karn 2003). }\end{array}$ \\
\hline & Run count & $\begin{array}{l}\text { This metrics indicate the total number of runs, where a run is two } \\
\text { consecutive fixations within same area of interest in a particular scene } \\
\text { (Uzzaman and Joordens } 2011 \text { ) }\end{array}$ \\
\hline & $\begin{array}{l}\text { Fixation-duration } \\
\text { mean }\end{array}$ & $\begin{array}{l}\text { This metric is widely used in eye-tracking studies and is an indication of } \\
\text { task difficulty and complexity (Pan et al. } 2004 \text { ). The higher values mean } \\
\text { that the participant needed further investigation to complete a task. }\end{array}$ \\
\hline & Number of fixations & $\begin{array}{l}\text { In most of the previous studies, a larger number of fixations indicates the } \\
\text { complex situation that decreased efficiency in searching for the desired } \\
\text { targets (Ehmke and Wilson 2007). }\end{array}$ \\
\hline \multirow{3}{*}{ 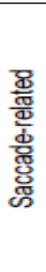 } & Saccade amplitude & $\begin{array}{l}\text { This metrics can be computed by dividing the distances between } \\
\text { consecutive fixations by the number of saccades (Goldberg and Kotval } \\
1999 \text { ). In computer-interface and -usability studies, larger saccade } \\
\text { amplitudes indicate well designed interfaces with sufficient cues that users } \\
\text { can find the desired targets rapidly (Goldberg et al. 2002). }\end{array}$ \\
\hline & $\begin{array}{l}\text { Number of } \\
\text { saccades }\end{array}$ & $\begin{array}{l}\text { More saccades reflect that participants spend more time searching for } \\
\text { important targets (Jacob and Kam } 2003 \text { ). This measure can be computed } \\
\text { from the number of fixations minus one (Goldberg and Kotval 1999). }\end{array}$ \\
\hline & $\begin{array}{l}\text { Saccade/ } \\
\text { ratio }\end{array}$ & $\begin{array}{l}\text { A larger ratio indicates that participants spend more time searching and } \\
\text { less time processing and comprehending targets (Ehmke and Wilson } \\
2007 \text { ). }\end{array}$ \\
\hline
\end{tabular}

Figure 1. Summary of the eye movement metrics (Bhoir, et al, 2015)

\section{Methodology}

Data were collected from participants through a questionnaire, eye-tracking software and postexperiment interview accordingly. The experiment was conducted to study participants' viewing behaviours along with attention distribution when viewing the homepage of Jumia.ng from the ecommerce domain and jamb.org.ng from the education domain. The websites were selected based on online rating found on Alexa.com - a web analytics tool that allows users to gain insight into what sites are most visited in regions and the categories (domains). Besides, the experiment was carried out to test participants' efficiency skills during the information search when they are required to make use of cognitive processing. Hence, this would help to determine the fixation rate of participants while surfing academic-based and e-commerce based websites.

A questionnaire was purposively distributed among thirty-five randomly selected final year students from the Faculty of Communication and Information Sciences, University of Ilorin, Nigeria. The questionnaire was designed to determine the students' experience from their frequent use of ecommerce platform, for transaction; as well as education-based platform responsible for admission process and procedures into a tertiary institution in Nigeria - jamb.org.ng.

The selective choice of thirty-five final year students is in line with the recommendation of Nielsen (2012), one of the contributory successes to the research study of this nature, is to recruit right participants for the process. For the right participants would have the essential qualities and skills demanded by the test; while the validity of the test depends on them. Also, these respondents were from the faculty which remains the hub of the university ICT. However, after filtering respondents' questionnaires, in addition to each student's academic excellence and skilful experience, fifteen participants were more considerable than others and therefore selected to participate in the test study. Besides, their selection for the test was based on their experience level with computer devices, online surfing, website interface design, technical know-how, and as research assistants. Interestingly, different studies were, respectively, conducted by Nielsen (2000) and Iqbal (2015), which depicted that testing with a small group of participants such as five participants, can uncover $80 \%$ of the problems in the system and the more the participants, the more likely it is to 
uncover more of the problems with the system. To buttress this point, Nielsen (2000) came out with a graph to show that no more problems were discovered from 11 to 15 test users, as shown in Figure 2. Besides, all of the participants were verified to have a normal vision or corrected-to-normal vision.

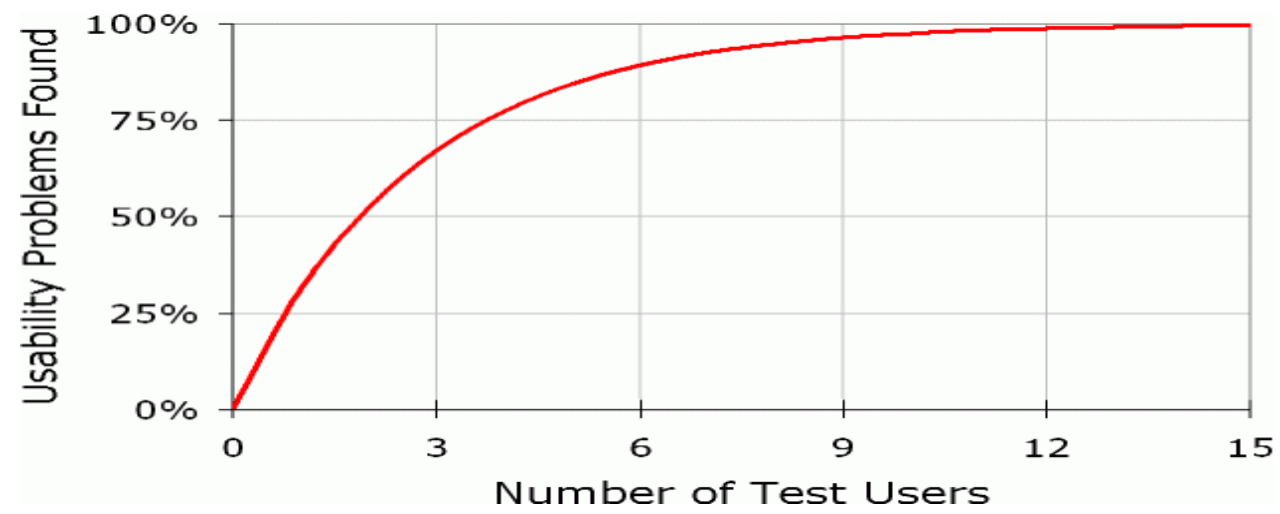

Figure 2. Showing Test users vs Problems discovered (Nielsen, 2000)

OGAMA software was used, as an eye-tracking tool, to record as well as to analyze eye and mouse tracking data from slideshow eye-tracking experiments concurrently. This is as a result of its main features, which include "database-driven pre-processing and filtering of gaze and mouse data, the creation of attention maps, areas of interest definition, saliency calculation, Levenshtein distance calculation and replay" (Ujbanyi, Sziladi, Katona, \& Kovari, 2019). To carry out the test, and to perform the selected task on the interface, each of the fifteen participants was given a total of 5 minutes.

\subsection{The Lab Setup}

Following the guidelines provided by Nielsen and Pernice (2009), the experiment was carried out in an improvised gaze laboratory of the Faculty. The gaze laboratory was well lit, and ventilated, to remove distractions and other external variables that might alter the result of the experiment. The laboratory was equipped with the following facilities:

- Observer room / participant room

- A computer with the OGAMA eye-tracking software installed.

- Two computer screens - one for the participant, connected to the computer, and extension of the other screen, so that the observer could monitor the participants.

- HDR Cable to connect both screens

- A Webcam that was used to capture the user's eye movement.

- USB Cables for the connection of the WebCam to the computer.

\section{Results and Discussion}

The first research question is what are the search and scan patterns used in interacting with the selected interfaces? At the end of the experiment and data collection, Areas of Interest (AOI) in each domain page was defined; this is the first step carried out to analyze the relationships linking eye movement parameters and dependent measures. AOI(s) are visual environments of interest defined by the research team (Balogun, Mabayoje, Adeniyi, \& Salihu, 2017; Menzi-Cetin et al., 2017). In this study, because the aim is to evaluate end users' usability using eye-tracking technology on the two selected domains, $\mathrm{AOI}(\mathrm{s})$ in this context is defined as visual environments of interest within a page that is to be compared using eye-tracking data, in terms of the number of fixations (a linger at a point for more than 300 milliseconds.) and the fixation duration, among others. The number of 
fixations is used to investigate the effectiveness and efficiency of software systems and it increases considerably in tasks that require too many operations. An example of the e-commerce site showing its homepage before and after gaze experiment was carried out as shown in Figures 3 and 4.

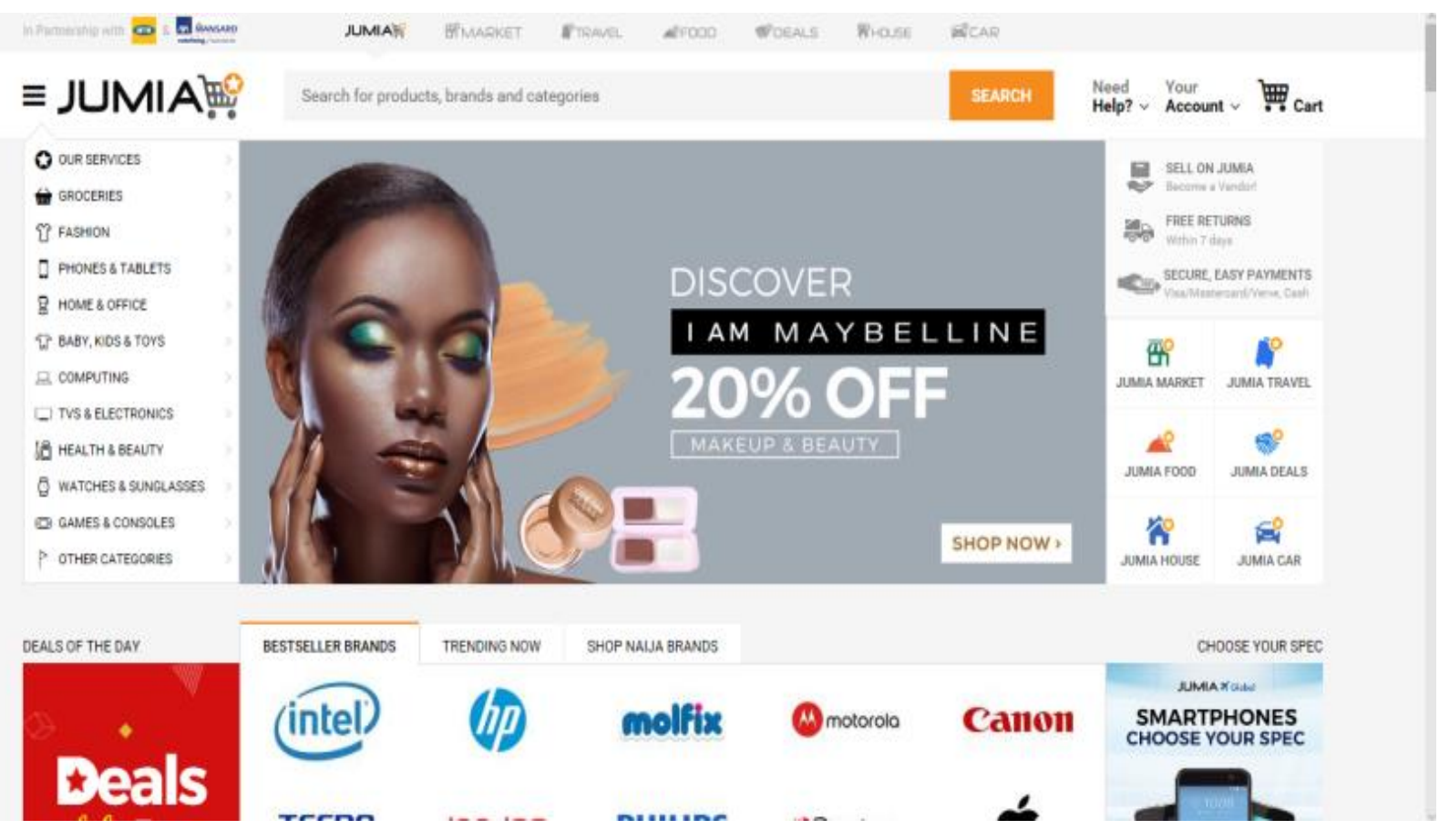

Figure 3. Jumia Homepage

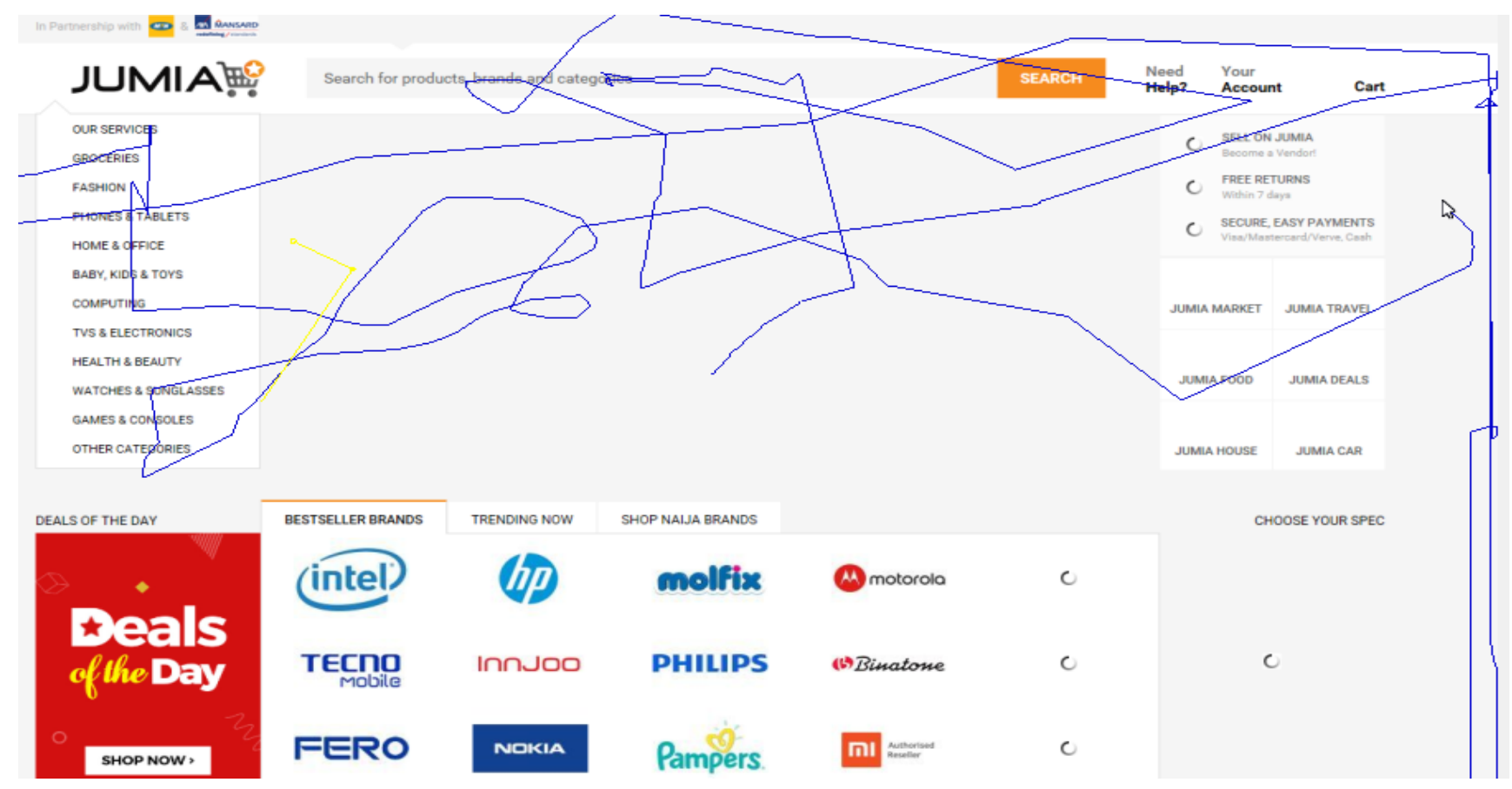

Figure 4. Gaze path on the Homepage 


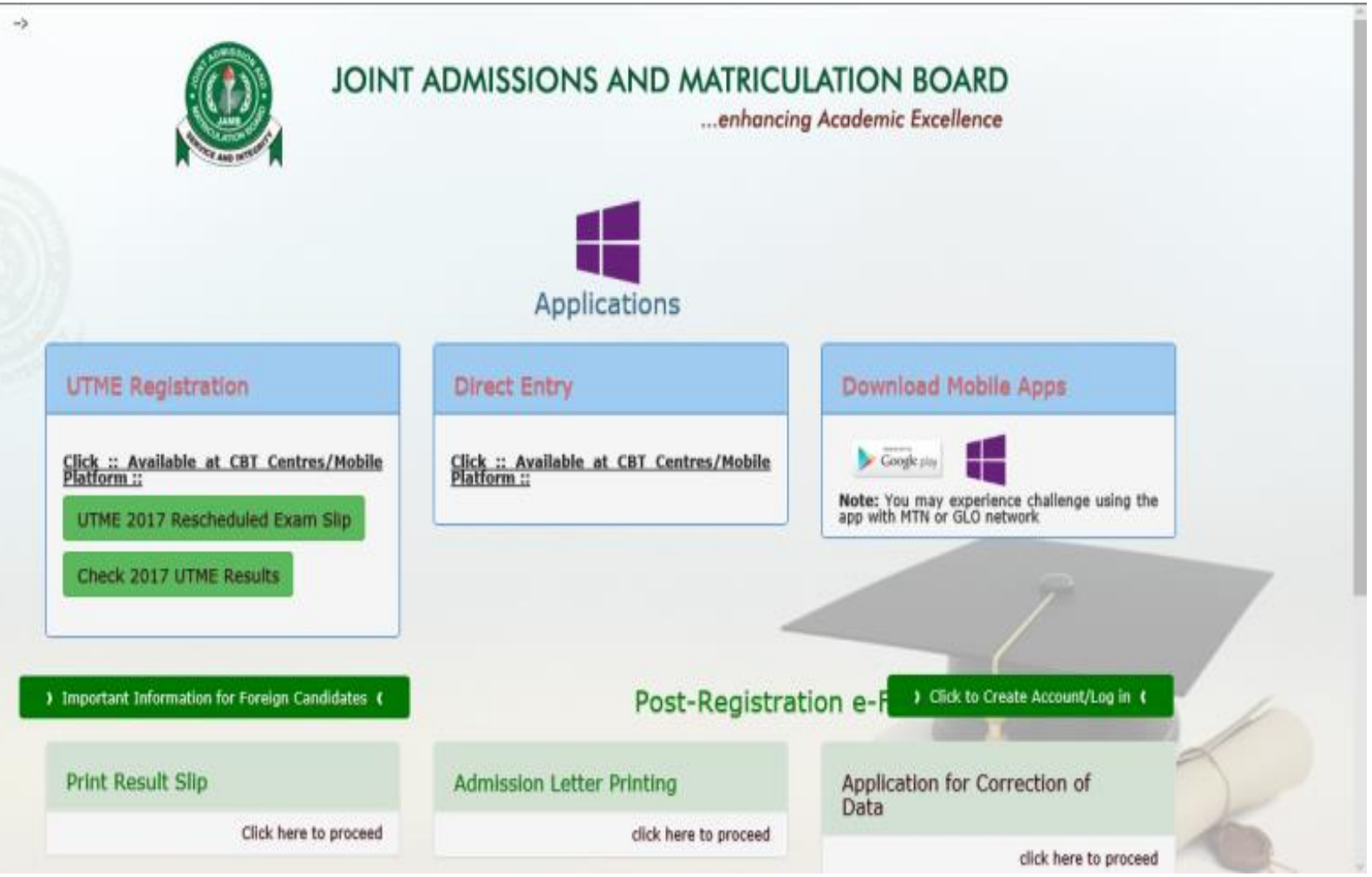

Figure 5. JAMB Portal

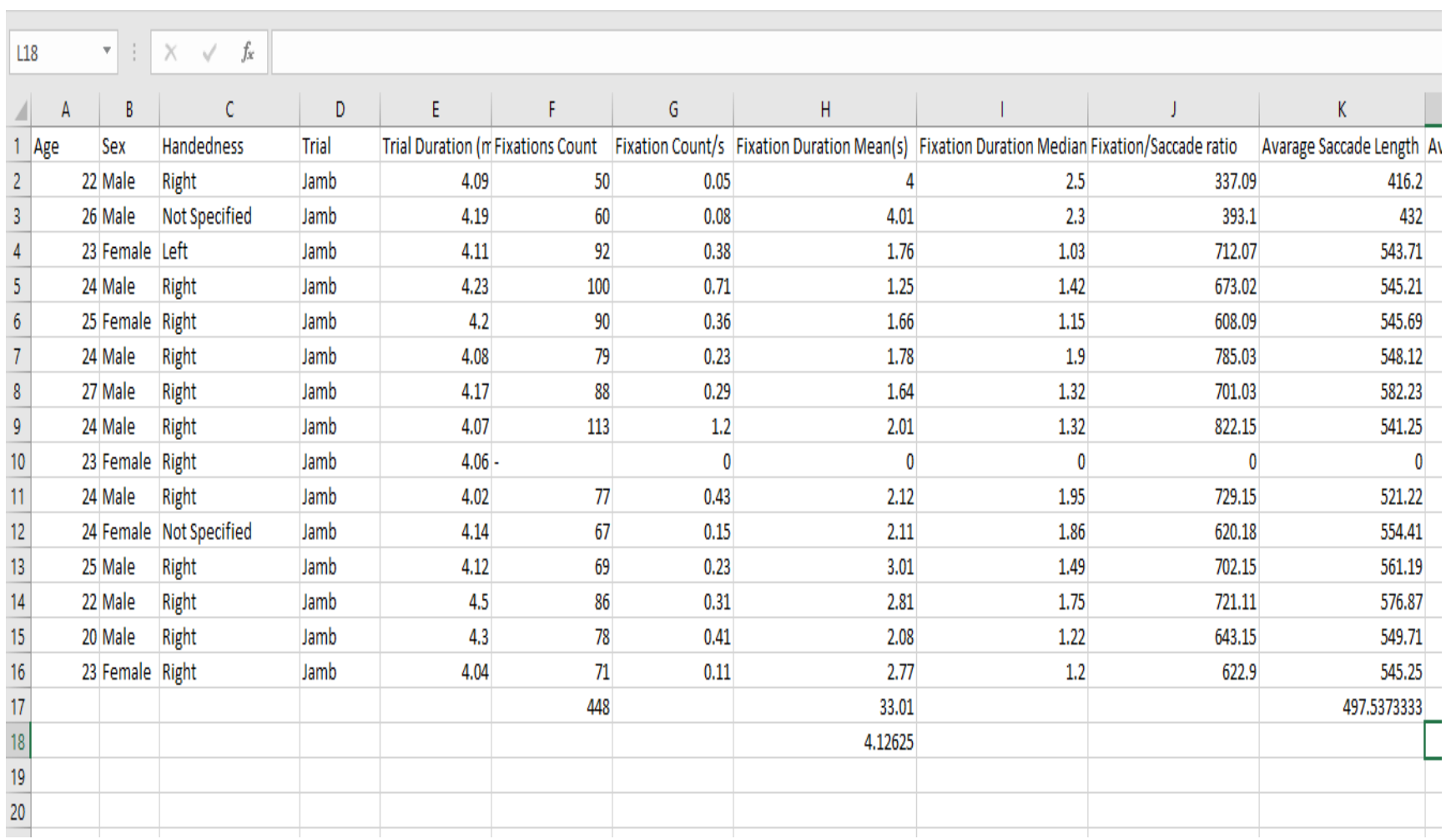

Figure 6. JAMB Portal Data Set

To represent the data graphically, an absolute fixation duration heat map was generated for each picture. The results were then analyzed using some eye movement metrics, for example, time to the fixation count, fixation velocity, fixation duration mean, fixation/saccade (rapid eye movements) 
ratio and average saccade amplitude. The participants were tested on only the activities on the Homepage of each of the two websites. The first website from the e-commerce domain was Jumia.com. Recorded fixations for the menu plus task item on the website were a total of 1305 data points at an average of 2.296 fixation/s. The average saccade length recorded for this website was at $521.08 \mathrm{px}$ as shown in table 1 . The search process was majorly influenced by factors such as images, colour and text; hence, designers can make use of these factors to guide the searching process of the users and organize the sub-operations well to reduce the number of fixations.

Table 1. Total data set recorded for the test on Jumia

\begin{tabular}{|c|c|c|c|}
\hline $\begin{array}{c}\text { Total fixation } \\
\text { point }\end{array}$ & Average Fixation/s & $\begin{array}{c}\text { Average Saccade } \\
\text { Length (px) }\end{array}$ & $\begin{array}{c}\text { Average Saccade } \\
\text { Velocity (px/s) }\end{array}$ \\
\hline 1305 & 2.296 & 521.08 & 44.15 \\
\hline
\end{tabular}

The overall fixations that were recorded for the menu, as well as task item on Jamb portal website, was a total of 448 data points at an average of 4.12 fixation/s. The average saccade length recorded for this website was at 497.53px as shown in table 2. There was, however, a case with participant number 9 that did not report any data, this was due to the technical issue with the calibration of the eye tracker.

Table 2. Fixation Counts for Jamb.org.ng

\begin{tabular}{|c|c|c|c|}
\hline $\begin{array}{c}\text { Total fixation } \\
\text { point }\end{array}$ & $\begin{array}{c}\text { Average } \\
\text { Fixation/s }\end{array}$ & $\begin{array}{c}\text { Average Saccade } \\
\text { Length (px) }\end{array}$ & $\begin{array}{c}\text { Average Saccade } \\
\text { Velocity (px/s) }\end{array}$ \\
\hline 448 & 4.12 & 497.53 & 2.40 \\
\hline
\end{tabular}

The second research question is what causes fixation on the interfaces by the users that create an area of interest heat maps? With an average of 2.29 fixations/s on the e-commerce interface that was dominated by pictures, the outcome of this study shows that users who view sites with a lot of picture elements on them have higher tendencies to quickly move from one interest point to another because of the ability of the site to get attention from the users of such an interface, this trend is likely to be consistent with all e-commerce sites since the goal is to drive more sales and increase the pleasure of the visual perception of the users. While the number of fixations tends to be correlated with time spent on a specific task, the unique value of eye-tracking lies in the qualitative eye movement analysis. By knowing where users looked at any given time during the search, the reasons for any inefficiencies or even search failures can be pinpointed. This finding supports that of Tonbuloğlu (2013) and Deotale (2011) that the items on the interface account for the number of fixations, and Sari et al., (2018) where eye fixation duration was found to be a key factor in recognising consumers' interest in a product. However, on the Jamb portal, there were lesser fixation counts on an average since there were just a handful of picture elements, and the site colour was consistent all over the site and this consequently reduced user's visual stress.

The next research question is whether there are any similarities in the design approach used by the selected domains? Areas, where similarities were found in the design approach, include the location of navigational items and font size of text content on the screen which makes reading easy. The outcome of the post-experiment interview is consistent with the data from the eye-tracking software. Research has shown that eye-tracking studies are usually conducted where results of 
traditional software usability are compared with that of the results from eye tracking (Wątróbski et al., 2017).

The last research question is on the common usability problems faced by users. The postexperiment interview revealed that one common usability problem experienced by users is too many information and colour to contend with on the web pages of jumia.com which is in the e-commerce domain. On the other hand, participants agreed that the jamb.org web pages had moderate colour and information, this establishes the fact that the two domains use different design approaches in some aspects. Other difficulties encountered include ambiguous labelling of items and poorly arranged navigation. Hence, website designers must recommend clear labelling of items, properly arranged navigational menu and moderate informational content as part of the existing several design principles to improve the usability of websites particularly e-commerce websites.

\section{Conclusion}

This study has examined fixation values for item search tasks on both e-commerce and educational website and discovered significant differences, particularly in the design choices in terms of, content, colour and picture elements on a website. Also, this study has been able to establish that the behavioural patterns of users interacting with an educational website and e-commerce website differ. Hence, there is a need to pay attention to current usability problems and design approach used in ecommerce and educational sites. While this study is not intended to serve as an exhaustive reference for every question on usability problems and causes of fixation on web design, its results have revealed that despite e-commerce site having scored well in beauty and use of multiple media elements, it performed poorly in terms of clearly helping users to achieve the goal of buying online by placing huge visual stress on the users having to battle with a lot of colors. User-friendly websites should as a matter of necessity enable users to complete their operations as soon as possible. Productivity is increased when the system provides this feature. The conclusions reached to assist in understanding the mindset of users which can be generalised to a larger population within the proximity of time and space and help in making recommendations for improved design of web interface. Future research can increase the number of participants and tasks performed in different areas, this can make the results obtained to be by more efficient, effective and accurate.

\section{References}

[1] Almeida, S., Mealha, O., \& Veloso, A. (2016). Video game scenery analysis with eye-tracking. Entertainment Computing, 14, 1-13.

[2] Amen, R. L., Agot Jr, W. C., Rosauro, O. R., \& Gamas, M. A. (2017). Finding the hidden dimension of global internet usage through fractal analysis. NMSCST Research Journal, 3(1).

[3] Aranyi, G., \& Van Schaik, P. (2016). Testing a model of user-experience with news websites. Journal of the Association for Information Science and Technology, 67(7), 1555-1575.

[4] Balogun, A. O., Mabayoje, M. A., Adeniyi, E. O., \& Salihu, S. A. (2017). A Framework for Coordinating Usability Engineering and Software Engineering Activities in the Development of Content Management Systems. Journal of Digital Innovations \& Contemporary Research In Science \& Engineering, 5(2).

[5] Bhoir, S. A., Hasanzadeh, S., Esmaeili, B. Dodd, M. D. \& Fardhosseini, M. S. (2015). "Measuring construction workers' attention using eye-tracking technology", 5th International and 11th Construction Conference, Vancouver, British Columbia, pp. 222.

[6] Boccignone, G., Ferraro, M., Crespi, S., Robino, C., \& de'Sperati, C. (2014). Detecting an expert's eye using a multiple-kernel Relevance Vector Machine.

[7] Busswell, G. (1935). How people look at pictures: A study of the psychology of perception in art: Chicago: University of Chicago Press.

[8] Card, S. K. (2018). The psychology of human-computer interaction: CRC Press. 
[9] Cheng, G., Poon, L. K., Lau, W. W., \& Zhou, R. C. (2019). Applying Eye Tracking to Identify Students' Use of Learning Strategies in Understanding Program Code. Paper presented at the Proceedings of the 2019 3rd International Conference on Education and Multimedia Technology.

[10] Deotale, P. A. (2011). Development and Usability Evaluation of an E-Learning Application using Eye tracking. Graduate Studies of Texas A\&M University.

[11] Filiopoulou, D., Rigou, M., \& Faliagka, E. (2019). Display Ads Effectiveness: An Eye-Tracking Investigation Business Transformations in the Era of Digitalization (pp. 205-230): IGI Global.

[12] Hsu, T.-C., Chang, S.-C., \& Liu, N.-C. (2018). Peer assessment of webpage design: a behavioral sequential analysis based on eye-tracking evidence. Journal of Educational Technology \& Society, 21(2), 305-321.

[13] Huey, E. B. (1908). The psychology and pedagogy of reading: The Macmillan Company.

[14] Ineson, E. M., Jung, T., Hains, C., \& Kim, M. (2013). The influence of prior subject knowledge, prior ability and work experience on self-efficacy. Journal of Hospitality, Leisure, Sport \& Tourism Education, 12(1), 59-69.

[15] Iqbal, F. (2015). Understanding User Interaction in a Video Game by using Eye Tracking and Facial Expressions Analysis. University of Tampere School of Information Sciences Human-Technology Interaction, 68.

[16] Jacob, R. J., \& Karn, K. S. (2003). Eye-tracking in human-computer interaction and usability research: Ready to deliver the promises. The mind's eye (pp. 573-605): Elsevier.

[17] Judd, C. H., McAllister, C. N., \& Steele, W. (1905). General introduction to a series of studies of eye movements by means of kinetoscopic photographs. Psychological Review Monographs, 7(1), 1-16.

[18] Just, M. A., \& Carpenter, P. A. (1976). The role of eye-fixation research in cognitive psychology. Behavior Research Methods \& Instrumentation, 8(2), 139-143.

[19] Kiefer, P., Giannopoulos, I., Raubal, M., Duchowski, A. (2017). Eye-tracking for spatial research: Cognition, computation. Spatial Cognition \& Computation, 17(2), 1-19.

[20] Krafka, K., Khosla, A., Kellnhofer, P., Kannan, H., Bhandarkar, S., Matusik, W., \& Torralba, A. (2016). Eye-tracking for everyone. Paper presented at the Proceedings of the IEEE conference on computer vision and pattern recognition.

[21] Lee, D.-j., Lee, J., Ju, J., \& Ahn, J.-H. (2019). Do Mobile Devices Change Shopping Behavior? An Eyetracking Approach. Paper presented at the 25th Americas Conference on Information Systems, Cancun, Mexico.

[22] Majaranta, P. (2011). Gaze Interaction and Applications of Eye Tracking: Advances in Assistive Technologies: Advances in Assistive Technologies: IGI Global.

[23] Majooni, A., Akhavan, A., \& Offenhuber, D. (2018). An Eye-Tracking Study on Usability and Efficiency of Blackboard Platform. Paper presented at the International Conference on Applied Human Factors and Ergonomics.

[24] Martin, C., Cegarra, J. \& Averty, P. (2011). Analysis of Mental Workload during En-route Air Traffic Control Task Execution Based on Eye-Tracking Technique. In: D. Harris (ed.), Springer Berlin Heidelberg, 592-597.

[25] Mason, L., Pluchino, P., \& Tornatora, M. C. (2016). Using eye-tracking technology as an indirect instruction tool to improve text and picture processing and learning. British Journal of Educational Technology, 47(6), 1083-1095.

[26] Matera, M., Rizzo, F. \& Carughi, G. (2006). Web Usability: Principles and Evaluation Methods. In: E. Mendes \& N. Mosley (eds.), Springer Berlin Heidelberg, 143-180.

[27] Menzi-Cetin, N., Alemdağ, E., Tüzün, H., \& Yıldız, M. (2017). Evaluation of a university website's usability for visually impaired students. Universal Access in the Information Society, 16(1), 151-160.

[28] Monty, R. A. (1975). An advanced eye-movement measuring and recording system. American Psychologist, 30(3), 331.

[29] Nielsen, J. (1993). Usability Engineering. Cambridge, MA: Academic Press.

[30] Nielsen, J. (1994b). Heuristic evaluation. In Nielsen, J., and Mack, R.L. (Eds.), Usability Inspection Methods, John Wiley \& Sons, New York, NY.

[31] Nielsen, J. (2000). Designing web usability: The practice of simplicity. Indianapolis, IN: New Riders Publishing.

[32] Nielsen, J. \& Pernice, K. (2009). Eyetracking Web Usability (1st ed.). Thousand Oaks, CA, USA: New Riders Publishing. 
[33] Nielsen, J. (2012). How Many Test Users in a Usability Study? Available at https://www.nngroup.com/articles/how-many-test-users/

[34] Pauly, L., \& Sankar, D. (2015). A novel method for eye tracking and blink detection in video frames. Paper presented at the 2015 IEEE International Conference on Computer Graphics, Vision and Information Security (CGVIS).

[35] Rothkegel, L. O., Schütt, H. H., Trukenbrod, H. A., Wichmann, F. A., \& Engbert, R. (2019). Searchers adjust their eye-movement dynamics to target characteristics in natural scenes. Scientific reports, 9(1), 112.

[36] Sari, J. N., Nugroho, L. E., Santosa, P. I., \& Ferdiana, R. (2018). The measurement of consumer interest and the prediction of product selection in E-commerce using the eye-tracking method. International Journal Intelligent Engineering System, 11(1), 30-40.

[37] Shanmuga V. K., Ngo, T., Eckstein, M., \& Manjunath, B. (2015). Eye-tracking assisted extraction of attentionally important objects from videos. Paper presented at the Proceedings of the IEEE Conference on Computer Vision and Pattern Recognition.

[38] Sikiru, I. A., Bello, O. W., \& Oyekunle, R. A. (2019). Evaluation of Websites of Nigerian State Governments using Heuristic Technique and Automated Tool. African Journal of Computing \& ICT, Vol. 12(3), pp. 1-17; available: https://afrjcict.net

[39] Tonbuloğlu, İ. (2013). Using the eye-tracking method and video record in a usability test of educational softwares and gender effects. Procedia-Social and Behavioral Sciences, 103, 1288-1294.

[40] Ujbanyi, T., Sziladi, G., Katona, J., \& Kovari, A. (2019). Pilot application of eye-tracking to analyze a computer exam test Cognitive Infocommunications, Theory and Applications (pp. 329-347): Switzerland, Springer.

[41] Wang, Q., Yang, S., Liu, M., Cao, Z. \& Ma, Q. (2014). An eye-tracking study of website complexity from cognitive load perspective. Decision Support Systems, 62, 1-10.

[42] Wątróbski, J., Jankowski, J., Karczmarczyk, A., \& Ziemba, P. (2017). Integration of eye-tracking based studies into e-commerce websites evaluation process with eQual and TOPSIS methods. Paper presented at the EuroSymposium on Systems Analysis and Design.

[43] Wu, C.-I. (2012). HCI and Eye Tracking Technology for Learning Effect. Procedia-Social and Behavioral Sciences, 64, 626-632.

[44] Yarbus, A. L. (2013). Eye movements and vision: Switzerland, Springer.

[45] Zhai, X., \& Enderle, J. D. (2016). Horizontal Saccadic Eye Movements to Visual and Auditory-Visual Double-Step Stimuli: Saccade Characteristics and Neural Input Estimations. Journal Biomed Eng Med Devic, 1(109), 2. 